\title{
Growth hormone releasing hormone
}

Physiological evidence of the hypothalamic control of pituitary growth hormone secretion has existed for many years and hypothalamic extracts from different species have been shown to stimulate growth hormone release both in vivo and in vitro. The isolation, characterisation, and synthesis of growth hormone releasing hormone has, however, taken longer to accomplish.

It has been known for some time that patients with carcinoid tumours may develop acromegaly, and the production by these tumours of biologically active substances with growth hormone releasing activity has been shown. In 1982, Thorner et al reported a patient with acromegaly whose pituitary histology showed hyperplasia of the somatotroph cells containing high concentrations of growth hormone on immunochemical staining. This patient had a pancreatic islet cell adenoma and after excision of the tumour the growth hormone releasing activity was extracted and growth hormone releasing hormone was isolated, characterised, and sequenced. ${ }^{2}$ Growth hormone releasing hormone was shown to be a 40 amino acid peptide with a free carboxyl terminal. Coincidentally, a 44 amino acid peptide was characterised from a second pancreatic tumour. ${ }^{3}$ The latter also contained small amounts of Cterminal shortened forms of growth hormone releasing hormone containing 37 and 40 amino acid residues.

\section{Studies in normal subjects}

Immunocytochemical studies have suggested that human hypothalamic growth hormone releasing hormone is very similar if not identical to human pancreatic growth hormone releasing hormone. Studies in normal subjects have shown that both synthetic growth hormone releasing hormone (1-40) and growth hormone releasing hormone (1-44) are potent stimulators of growth hormone release and it seems likely that the maximal response to the two analogues is identical. A recent study ${ }^{4}$ compared the dose-response characteristics of releasing hormone $(1-40)$ and the shorter analogue releasing hormone (1-29) $\mathrm{NH}_{2}$ and showed that the latter was an equally effective stimulus of growth hormone release and it is much cheaper to synthesise by available techniques. Unpublished animal studies suggest that shorter forms have considerably reduced activity. In terms of amplitude of peak growth hormone release, there seems little justification for using more than $100 \mu \mathrm{g}$ as a clinical test for the amount of readily releasable growth hormone in the pituitary. Growth hormone responses to releasing hormone, administered both intravenously and intranasally, have shown considerable individual variation in normal adults. Variability of response was also shown in endocrinologically normal, short children.

\section{Detection of a hypothalamic lesion}

Hypopituitarism in childhood can be divided into two main aetiological groups - firstly idiopathic, and secondly that associated with a proved central nervous system abnormality. A third group of children with hypopituitarism after cranial irradiation is emerging. Many children with idiopathic, isolated growth hormone deficiency may in fact have a primary hypothalamic defect of growth hormone releasing hormone synthesis or secretion, and the availability of synthetic releasing hormone for clinical studies allows this to be detected.

Growth hormone responsiveness to releasing hormone was first shown in growth hormone deficient children by Grossman et al, and in a more recent study ${ }^{5}$ eight children and young adults showed normal or only slightly reduced growth hormone responses to releasing hormone in considerable contrast to the clearly growth hormone deficient response to insulin hypoglycaemia. Three of these responders had structural hypothalamic lesions (one germinoma, one hamartoma, one histiocytosis $\mathrm{X}$ ), and five had idiopathic hypopituitarism. Patients with growth hormone deficiency after irradiation for primary brain tumours in childhood may also preserve the growth hormone response to growth hormone releasing hormone compared with that to insulin hypoglycaemia.

The finding of a growth hormone response to releasing hormone with an absent response to hypoglycaemia provides evidence of a defect in the hypothalamic synthesis, release, or delivery of endogenous growth hormone releasing hormone. Our data and those of Schriock ${ }^{6}$ suggest that most children with idiopathic growth hormone deficiency may have a primary hypothalamic defect. We do not yet know whether patients who fail to respond to the first dose of releasing hormone can be 'primed' with repeated doses and then become responders. High resolution computed tomography of the hypothalamic-pituitary region has detected hypothalamic 
abnormalities in several patients with so-called idiopathic growth hormone deficiency who have shown responses to growth hormone releasing hormone.

\section{Potential for treatment of growth hormone deficiency}

The treatment of children suffering growth hormone deficiency of hypothalamic origin with synthetic releasing hormone would be more physiological than their treatment with human growth hormone. The treatment potential of growth hormone releasing hormone depends on its ability to increase and maintain plasma somatomedin concentrations and thereby induce normal linear growth. A significant increase of somatomedin $\mathrm{C}$ during five days of intermittent administration of growth hormone releasing hormone (1-40) has recently been reported. ${ }^{7}$ We have seen an acute rise of somatomedin $C$ into the normal range after a single bolus infusion of releasing hormone in a child with hypopituitarism, and a maintained rise accompanying an increase in growth hormone concentrations during releasing hormone infusion. A significant increase in height velocity in one growth hormone deficient child during a six month period of pulsatile subcutaneous releasing hormone administration has recently been reported in abstract form.

It is very likely, therefore, that growth hormone releasing hormone treatment may stimulate growth in many growth hormone deficient children. ${ }^{8}$ Human growth hormone extracted from cadaveric pituitaries is in short supply and expensive to produce. Synthetic releasing hormone or its analogues may provide a new approach to the treatment of growth hormone deficiency, thus reducing the demand for human growth hormone. The optimum dose and mode of administration of this new hypothalamic hormone is the subject of active research in a number of centres at the present time.

References

1 Thorner MO, Perryman RL, Cronin MJ, et al. Somatotroph hyperplasia-successful treatment of acromegaly by removal of a pancreatic islet cell tumour secreting a growth hormone releasing factor. J Clin Invest 1982;10:66-71.

2 Rivier J, Speiss J, Thorner M, Vale W. Characterisation of a growth hormone-releasing factor from a human pancreatic islet tumour. Nature 1982;300:276-7.

${ }^{3}$ Guillemin R, Brazeau P, Bohlen P, Esch F, Ling N, Wehrenberg WB. Growth hormone-releasing factor from a human pancreatic tumour that caused acromegaly. Science 1982;218: 585-7.

4 Grossman A, Lytras N, Savage MO, et al. Growth hormone releasing factor: comparison of two analogues and demonstration of hypothalamic defect in growth hormone release after radiotherapy. $\mathrm{Br}$ Med $J$ 1984;288:1785-7.

5 Grossman A, Savage MO, Lytras $\mathrm{N}$ et al. Responses to analogues of growth hormone-releasing hormone in normal subjects and in growth hormone deficient children and young adults. Clin Endocrinol 1984;21:321-9.

6 Schriock EA, Lustig RH, Rosenthal SM, Kaplan SL, Grumbach MM. Effect of growth hormone $(\mathrm{GH})$-releasing hormone $(\mathrm{GRH})$ on plasma $\mathrm{GH}$ in relation to magnitude and duration of GH deficiency in 26 children and adults with isolated GH deficiency or multiple pituitary hormone deficiencies: evidence for hypothalamic GRH deficiency. J Clin Endocrinol Metab 1984;58:1043-9.

7 Borges JLC, Blizzard RM, Evans WS, et al. Stimulation of growth hormone $(\mathrm{GH})$ and somatomedin $\mathrm{C}$ in idiopathic $\mathrm{Gh}$ deficient subjects by intermittent pulsatile administration of synthetic human pancreatic tumour $\mathrm{GH}$-releasing factor. $J$ Clin Endocrinol Metab 1984;59:1-6.

8 Thorner MO, Reschke J, Chitwood J, et al. Acceleration of growth in two children treated with human growth hormonereleasing factor. $N$ Engl J Med 1985;312:4-9.

M O SAVAge ANd G M Besser Departments of Endocrinology and Child Health, St Bartholomew's Hospital, London ECIA $7 B E$ 